\title{
Application of a mass-balance model to a Himalayan glacier
}

\author{
Rijan Bhakta Kayastha, ${ }^{1}$ Tetsuo Ohata, ${ }^{2}$ Yutaka Ageta ${ }^{1}$ \\ ${ }^{1}$ Institute for Hydrospheric-Atmospheric Sciences, Nagoya University, Nagoya 464-8601, Japan \\ ${ }^{2}$ Institute of Low Temperature Science, Hokkaido University, Sapporo 060-0819, Japan
}

\begin{abstract}
A mass-balance model based on the energy balance at the snow or ice surface is formulated, with particular attention paid to processes affecting absorption of radiation. The model is applied to a small glacier, Glacier AX010 in the Nepalese Himalaya, and tests of its mass-balance sensitivity to input and climatic parameters are carried out. Calculated and observed area-averaged mass balances of the glacier during summer 1978 (June-September) show good agreement, namely -0.44 and $-0.46 \mathrm{~m}$ w.e., respectively.

Results show the mass balance is strongly sensitive to snow or ice albedo, to the effects of screening by surrounding mountain walls, to areal variations in multiple reflection between clouds and the glacier surface, and to thin snow covers which alter the surface albedo. In tests of the sensitivity of the mass balance to seasonal values of climatic parameters, the mass balance is found to be strongly sensitive to summer air temperature and precipitation but only weakly sensitive to relative humidity.
\end{abstract}

\section{INTRODUCTION}

Mountain glaciers play an important role in local hydrological processes, so it is worth knowing how mass balance varies with changes in parameters such as surface conditions and climate. Many hydroelectric stations have been established or are planned in the Himalayan region, where the main source of water is glacier meltwater and snowmelt runoff from glacierized basins; the former is closely related to summer mass balance. In order to predict possible changes in mass balance, and to assess the long-term availability of water, it is necessary to study the sensitivity of glacier mass balance to climatic parameters.

There have been a number of studies on the relationship between mass balance and climate. Ageta and others (1980), in a study of summer mass balance in the Nepalese Himalaya, established an empirical relation between ablation and air temperature. Kuhn (1989) expanded the number of variables, formulating mass balance in terms of seasonal values of accumulation, radiation balance, air temperature and humidity. Oerlemans and Hoogendoorn (1989) developed an altitudedependent mass-balance model which was based on the energy balance of the ice or snow surface; precipitation was included in a parameterized form, and the slope and exposure of the ice or snow surface were taken into account. Braithwaite and Olesen (1990) calculated ablation on two outlet glaciers from the Greenland ice sheet by a simple energy-balance model which used climate data. Oerlemans (1993) presented a model for the mass balance of glaciers in the Alps based on the energy balance at the surface; the various fluxes were parameterized in such a way that altitudinal dependence was taken into account. Munro (1991) used a surface energy-exchange model of glacier melt and net mass balance to simulate ablation and net mass balance on Peyto Glacier, Canada. Arnold and others (1996) developed and tested a surface energy-balance model to calculate rates of surface melting on a glacier in Switzerland, using a digital elevation model of the glacier surface and surrounding topography together with meteorological data from a site in front of the glacier. They determined hourly or daily energy-balance components and calculated melting over the entire glacier surface with a spatial resolution of $20 \mathrm{~m}$. Models such as these, which use surface energy-balance concepts to calculate ablation, have not been applied to Himalayan glaciers previously.

Climatic conditions in the Himalaya are different from those of other regions. Himalayan glaciers are located in a monsoon area, and most annual accumulation occurs in summer. Ageta and Higuchi (1984) referred to them as "the summer-accumulation type". Variations in air temperature and relative humidity are high at the beginning and at the end of the summer monsoon season, and incoming solar radiation is quite high throughout the season, despite the extensive cloud cover.

Radiation is the dominant component of the heat balance in the Himalaya (Ohata and Higuchi, 1980). Therefore, special attention must be given to the parameters and processes which influence radiation. For example:

(1) Glaciers in the Himalaya have a wide range of surface albedo due to the presence of dirt on the surface.

(2) When new snow falls, the albedo of the underlying surface affects the surface albedo if the layer of new snow is thin. Usually, the effective albedo of thin new-snow layers is less than that of the thicker snow layers (Ohata and others, 1980).

(3) Mountain walls have an appreciable screening effect on shortwave radiation owing to the high relief of Himalayan topography. The intensity of downward longwave radiation, from both the atmosphere and mountain walls, also depends on the surrounding topography.

(4) Shortwave radiation is reflected between the glacier surface and clouds; thus on small glaciers, whose size is com- 
parable to the cloud height, global radiation depends on the size of the glacier (Ohata, 1991).

The main objective of this paper is to formulate a massbalance model to study the characteristics of a small glacier in the Himalaya. First, an energy-balance model is used to calculate ablation, using meteorological parameters to drive the model. A unique aspect of the model is the classification of snow into three types - new, old and dirty - to specify the condition, and hence albedo, of the glacier surface. In addition, processes (2) to (4) described above are considered in the model. Second, the sensitivity of glacier mass balance to input parameters and to the various processes is tested. Third, the sensitivity of the mass balance to climatic parameters (driving parameters) is also tested.

Although the lower parts of large glaciers in the Himalaya are typically covered with thick debris layers, the present model does not include the effect of this debris. The model is applied to Glacier AX010 (Fig. 1), a small glacier where detailed glaciological and meteorological observations were carried out in 1978. As a typical debris-free glacier in the eastern Nepalese Himalaya, this glacier has been chosen for long-term study.

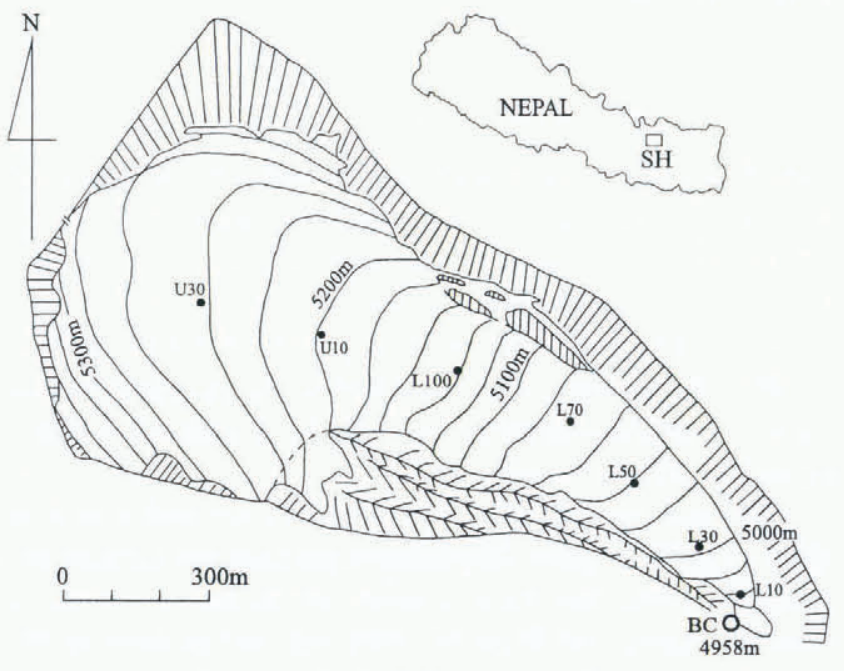

Fig. 1. Glacier AX010, Shorong Himal, Nepal. SH is the location of the Shorong area.

\section{A MODEL FOR GLACIER MASS BALANCE}

The structure of the model to calculate the specific surface mass balance is shown in Figure 2.

The energy available for melting is calculated using the energy-balance concept and measured or observed meteorological parameters and surface conditions. It is assumed that all rain and meltwater runs off, as significant amounts of superimposed ice were not observed on the glacier to which the model is applied (Ageta and others, 1980). This is because ice temperatures are not cold enough to freeze percolating water. The effect of percolation on snow density and on albedo is not calculated in the model, but the effect is incorporated by parameterizing the surface conditions, as described later.

\subsection{Surface energy balance}

The basic energy-balance equation employed is:

$$
Q_{\mathrm{M}}=K^{*}+L^{*}+Q_{\mathrm{S}}+Q_{\mathrm{L}}+Q_{\mathrm{G}}
$$

where $Q_{\mathrm{M}}$ is the energy used for melting snow and ice, $K^{*}$ is the net shortwave-radiation flux, $L^{*}$ is the net longwaveradiation flux $Q_{\mathrm{S}}$ is the sensible-heat flux, $Q_{\mathrm{L}}$ is the latentheat flux and $Q_{\mathrm{G}}$ is the heat conduction at the glacier surface. Heat transport by precipitation is assumed to be negligible. Incoming energy is taken as positive, and outgoing as negative.

\section{(a) Shortwave-radiation flux}

The net shortwave-radiation flux, $K^{*}$, is calculated as:

$$
K^{*}=G(1-\alpha)
$$

where $G$ is the global radiation $\left(\mathrm{W} \mathrm{m}^{-2}\right)$ and $\alpha$ is the surface albedo.

Field observations at Glacier AX010 have shown that the presence of even a thin snow layer during the ablation season has an important effect on albedo. This was taken into account using a relationship similar to that used by Ohata and others (1980) relating the depth of new snow to the albedo of the underlying surface:

$$
\begin{aligned}
& \alpha(d)=5.69 \sqrt{d}\left(\alpha_{\mathrm{s}}-\alpha_{\mathrm{b}}\right)+\alpha_{\mathrm{b}} \quad \text { for } \quad d \leq 0.02 \mathrm{~m} \\
& =0.69 \quad \text { for } d>0.02 \mathrm{~m}
\end{aligned}
$$

where $\alpha(d)$ is the surface albedo when the thickness of new snow is $d$ in meters, $\alpha_{\mathrm{s}}$ is the albedo of new snow, and $\alpha_{\mathrm{b}}$ is the observed albedo of the underlying surface before the snowfall. Based on measurements, the albedo of new snow is assumed to be 0.69 when the thickness exceeds $0.02 \mathrm{~m}$. Since the effect of such thin snow layers is most pronounced on the lower part of the glacier, and most new snow melts within a few days, the change from new snow into old snow is not considered.

In the presence of clouds, high-albedo snow and ice surfaces intensify the effect of multiple reflections between the surface and the clouds. This leads to higher values of $K^{*}$ than would be predicted solely from the fraction of shortwave solar radiation penetrating the cloud cover and the surface albedo. Because meteorological parameters are frequently observed close to the ground near the glacier, where measurements can be monitored easily, it is necessary to consider the effect of such multiple reflections when calculating the solar-radiation input to the glacier surface. According to Ohata (1991), the global radiation, $G_{\mathrm{R}}$, observed at a reference point on the ground can be converted to global radiation, $G_{\mathrm{P}}$, at a point on the glacier, taking into consideration the multiple-reflection effect and assuming the same cloud parameters at both points, by the following relation:

$$
G_{\mathrm{P}}=\frac{1-\alpha_{\mathrm{R}} \gamma c}{1-\alpha_{\mathrm{P}} \gamma c} G_{\mathrm{R}}
$$

where $\gamma$ is the reflectance of the clouds, $c$ is the decimal cloud cover, and $\alpha_{\mathrm{P}}$ and $\alpha_{\mathrm{R}}$ are the areal albedo of the point on the glacier and of the reference point, respectively. In the simulation, the height of the cloud base is assumed to be $200 \mathrm{~m}$ due to the high elevation of the glacier surface. Similarly, the area influenced by the cloud reflectance is taken to be an area whose diameter is twice the height of the cloud base $(400 \mathrm{~m})$. The reflectance of the clouds is taken as 0.62 , based on an average value for cumulonimbus and cirrus clouds (Reynolds and others, 1975). 


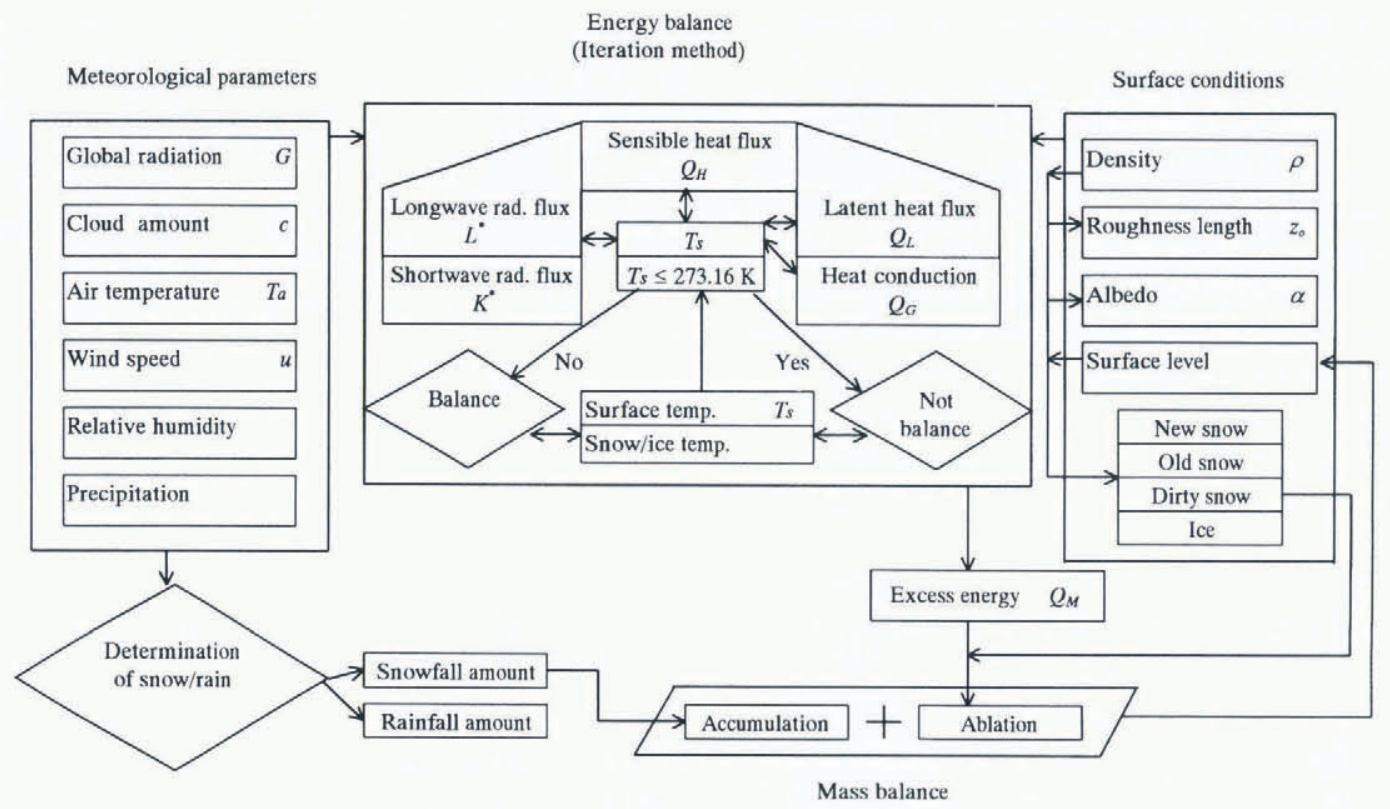

Fig. 2. Structure of the model.

\section{(b) Longwave-radiation flux}

The longwave radiation emitted from the snow surface, $L_{\uparrow}$, can be calculated from the Stefan-Boltzmann law:

$$
L_{\uparrow}=\varepsilon_{\mathrm{s}} \sigma_{\mathrm{s}} T_{\mathrm{s}}^{4}
$$

where $\sigma_{\mathrm{s}}$ is the Stefan-Boltzmann constant $\left(5.67 \times 10^{-8}\right.$ $\left.\mathrm{W} \mathrm{m}{ }^{-2} \mathrm{~K}^{-4}\right), T_{\mathrm{s}}$ is the surface temperature $(\mathrm{K})$, and $\varepsilon_{\mathrm{s}}$ is surface emissivity, which was assumed to be unity.

The downward longwave radiation under clear skies, $L_{\downarrow}$, is calculated from:

$$
L_{\downarrow 0}=\sigma_{\mathrm{s}} T_{\mathrm{a}}{ }^{4}\left(0.62+0.005 \sqrt{e_{\mathrm{a}}}\right)
$$

(Kuz'min, 1961) where $T_{\mathrm{a}}$ is the air temperature $(\mathrm{K})$ and $e_{\mathrm{a}}$ is the vapor pressure of the air $(\mathrm{Pa})$.

In a valley, radiation from the atmosphere is reduced wherever part of the sky is obscured by the valley walls. However, the valley floor will receive longwave radiation from the valley walls in an amount governed by a form of Equation (5). Marks (1979) considered this effect by using a thermal-view factor, $V_{\mathrm{f}}$. The fraction of the hemisphere which is obscured by the valley walls is determined from elevations of the surrounding terrain. The unobscured part is termed the thermal-view factor, and is expressed as a number between 0 and 1 , thus:

$$
V_{\mathrm{f}}=\cos ^{2}(90-H)
$$

(Lee, 1962) where $H$ is the average horizon angle measured from the zenith.

Thus, in mountainous areas the longwave radiation incident at a point under clear skies, including the topographic effect, $L_{\downarrow}$, is given by:

$$
L_{\downarrow}=L_{\downarrow 0} V_{\mathrm{f}}+\left(\sigma_{\mathrm{s}} T_{\mathrm{a}}^{4}\right)\left(1-V_{\mathrm{f}}\right) .
$$

The second term on the right side of Equation (8) is the contribution from the valley sides in which the temperature of the valley sides is assumed to be the same as the air temperature.

Clouds have a strong influence on longwave-radiation exchange because they are almost perfect radiators. The most common approach to estimating the effect of clouds upon the net longwave radiation is to modify the cloudless- sky value by a non-linear cloud term. Thus, the net longwave radiation under cloudy skies, $L^{*}$, is given by:

$$
L^{*}=\left(L_{\downarrow}-L_{\uparrow}\right)\left(1-c^{2}\right)
$$

where $c$ is the decimal cloud cover assuming a fog-type cloud (Oke, 1987).

\section{(c) Sensible-heat flux}

Sensible-heat flux, $Q_{\mathrm{S}}$, is determined from:

$$
Q_{\mathrm{S}}=\rho_{\mathrm{a}} c_{\mathrm{p}} D_{\mathrm{s}}\left(T_{\mathrm{a}}-T_{\mathrm{s}}\right)
$$

where $\rho_{\mathrm{a}}$ is the density of air, $c_{\mathrm{p}}$ is the specific heat of air at constant pressure, and $D_{\mathrm{s}}$ is the turbulent-transfer coefficient under stable conditions (assumed here to be the same for transfer of either heat or water vapor).

The turbulent-transfer coefficient under stable conditions over snow is obtained by converting the turbulenttransfer coefficient for neutral-stability conditions to that for stable conditions using the bulk Richardson number, Ri. For neutral-stability conditions (in which buoyancy effects are absent) in the boundary layer, the turbulenttransfer coefficient, $D_{\mathrm{n}}$, is given by:

$$
D_{\mathrm{n}}=\frac{\mathrm{k}^{2} u}{\left[\ln \left(z / z_{0}\right)\right]^{2}}
$$

where $\mathrm{k}$ is the von Kármán constant $(0.4 \mathrm{l}), u$ is the wind speed $\left(\mathrm{m} \mathrm{s}^{-1}\right), z$ is the measurement level above the snow or ice surface, and $z_{0}$ is the aerodynamic-roughness length. $D_{\mathrm{s}}$ is then calculated from:

$$
D_{\mathrm{s}}=\frac{D_{\mathrm{n}}}{(1+10 \mathrm{Ri})}
$$

(Braun, 1985) where the $\mathrm{Ri}$ is calculated from:

$$
\mathrm{Ri}=g z \frac{\left(T_{\mathrm{a}}-T_{\mathrm{s}}\right)}{u^{2}\left(T_{\mathrm{a}}+273\right)}
$$

where $g$ is the acceleration due to gravity $\left(9.8 \mathrm{~m} \mathrm{~s}^{-2}\right)$.

(d) Latent-heat flux

The latent-heat flux $Q_{\mathrm{L}}$ is determined using:

$$
Q_{\mathrm{L}}=L \rho_{\mathrm{a}} D_{\mathrm{s}}\left(q_{\mathrm{a}}-q_{\mathrm{s}}\right)
$$

where $L$ is the latent heat of evaporation $\left(2.5 \times 10^{6} \mathrm{~J} \mathrm{~kg}^{-1}\right), q_{\text {a }}$ is the specific humidity of air at measurement level $z$, and $q_{\mathrm{s}}$ 
is the specific humidity at the snow surface. The term $\left(q_{\mathrm{a}}-q_{\mathrm{s}}\right)$ is given by:

$$
q_{\mathrm{a}}-q_{\mathrm{s}}=(0.622 / p)\left(e_{\mathrm{a}}-e_{\mathrm{s}}\right)
$$

where $p$ is atmospheric pressure, $e_{\mathrm{a}}$ is vapor pressure of the air, and $e_{\mathrm{s}}$ is the saturation vapor pressure at the snow surface (all in $10^{3} \mathrm{~Pa}$ ).

$e_{\mathrm{a}}$ is calculated from the saturation vapor pressure over a plane surface of pure water using the Goff-Gratch formulation (List, 1971) and the prevailing relative humidity. $e_{\mathrm{s}}$ is assumed to be the same as the saturation vapor pressure over a plane surface of pure water at surface temperature $T_{\mathrm{s}}$.

\section{(e) Heat conduction}

Assuming no meltwater percolation, heat conduction into the glacier from the surface, $Q_{\mathrm{G}}$, is calculated from:

$$
Q_{\mathrm{G}}=K \frac{\Delta T}{\Delta z}
$$

where $K$ is the thermal conductivity of snow $\left(\mathrm{W} \mathrm{m}^{-1} \mathrm{~K}^{-1}\right.$ ) and $\Delta T / \Delta z$ is the temperature gradient. The temperature profile from the surface to ten different points $(0.02 \mathrm{~m}$, $0.04 \mathrm{~m}, 0.08 \mathrm{~m}, 0.16 \mathrm{~m} \ldots 10.24 \mathrm{~m})$ vertically below the surface is calculated with the thermodynamic energy equation:

$$
\rho c_{\mathrm{p}} \frac{\mathrm{d} T_{\mathrm{s}}}{\mathrm{d} t}=\frac{\partial}{\partial z}\left(K \frac{\Delta T}{\Delta z}\right)
$$

where $\rho$ is the density of snow or ice $\left(\mathrm{kg} \mathrm{m}^{-3}\right), t$ is time and $c_{\mathrm{p}}$ is the specific heat capacity of ice $\left(2009 \mathrm{~J} \mathrm{~kg}^{-1} \mathrm{~K}^{-1}\right)$. Equation (17) is integrated numerically. The change in surface temperature is assumed to be due only to heat conduction (through the snow or ice normal to the surface).

The thermal conductivity, $K$, is calculated from:

$$
K=2.1 \times 10^{-2}+4.2 \times 10^{-4} \rho+2.2 \times 10^{-9} \rho^{3}
$$

(Van Dusen, 1929).

\subsection{Mass balance}

Based on the algebraic sum of the individual surface energybalance components and solid precipitation, $P_{\mathrm{s}}$, the mass balance, $\mathrm{MB}$, is calculated from:

$$
\mathrm{MB}=-\frac{Q_{\mathrm{M}}}{L_{\mathrm{f}}}+P_{\mathrm{s}}
$$

where $L_{\mathrm{f}}$ is the latent heat of fusion $\left(3.34 \times 10^{5} \mathrm{~J} \mathrm{~kg}^{-1}\right)$.

\subsection{Calculation procedure}

The model calculates the energy available for melting snow or ice, $Q_{\mathrm{M}}$, every hour from Equation (1) using an iteration method. The energy-balance calculations are performed using hourly meteorological data with initial surface conditions (Fig. 3), and the initial surface snow temperature $(269.5 \mathrm{~K})$ based on observations and measurements on 25 May 1978. Because heat conduction is effective only near the glacier surface, it is calculated between the snow or ice surface and $0.02 \mathrm{~m}$ below the surface every $5 \mathrm{~min}$, and summed up every hour. The model calculates the surface temperature, which balances the right hand side of Equation (1): if the surface temperature is below $0^{\circ} \mathrm{C}, Q_{\mathrm{M}}$ is taken as zero. If the surface temperature rises above $0^{\circ} \mathrm{C}$, the excess heat calculated by fixing the surface temperature at $0^{\circ} \mathrm{C}$ is taken as $Q_{\mathrm{M}}$. This $Q_{\mathrm{M}}$ is used to calculate the amount of ablation. At the end of a 1 hour calculation, the resulting surface-snow or ice temperature is used to begin the next iteration.

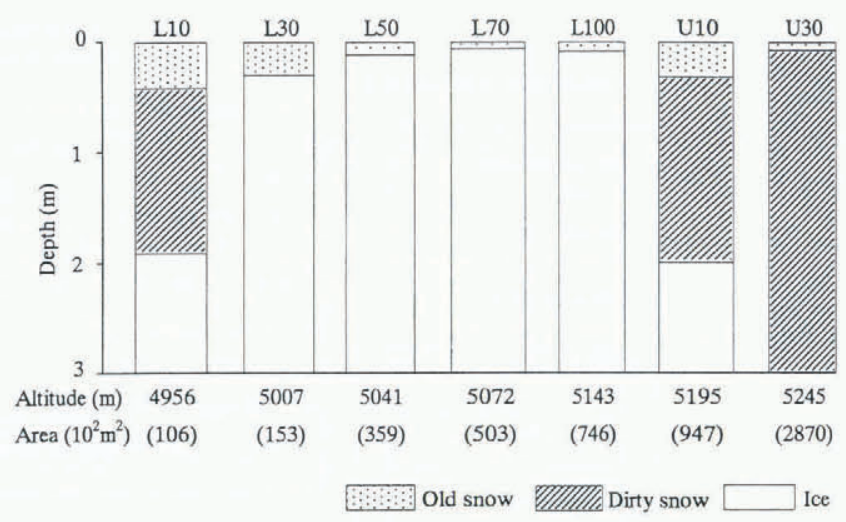

Fig. 3. Initial snow and ice conditions at various points on Glacier AX010 on 25 May 1978. The altitude and the area represented by each point are shown.

If the calculated mass balance indicates that all snow has melted and ice has appeared, the values of the surface albedo, density and roughness length are altered to reflect those of ice (Table 1). If more than $0.02 \mathrm{~m}$ of new snow is added to the surface, the values assigned to these parameters are those of new snow, and the calculation for the next hour begins with these new values together with the appropriate meteorological and surface parameters. As mentioned above, intermediate values are assigned if the depth of new snow is less than $0.02 \mathrm{~m}$. This process of calculation continues for all hours of the day every day.

Table 1. Values of density and thermodynamic parameters for the various snow and ice types used in the simulation (the values are based on observations)

Newsnow Oldsnow Dirtysnow Ice

\begin{tabular}{lcccc}
\hline Albedo & 0.69 & 0.60 & $0.33-0.50$ & $0.14-0.33$ \\
Roughness length $\left(\times 10^{-3} \mathrm{~m}\right)$ & 0.5 & 0.5 & 1 & 5 \\
Density $\left(\mathrm{kg} \mathrm{m}^{-3}\right)$ & 320 & 430 & 450 & 850 \\
\hline
\end{tabular}

\section{APPLICATION OF THE MODEL}

\subsection{Description of the glacier}

As noted, the model has been applied to Glacier AX010 (Fig. 1), a small mountain glacier of the summer-accumulation type in Shorong Himal, east Nepal, using meteorological and other observations from the Japan-Nepal Joint Glaciological Expedition in Nepal during the 1978 summer monsoon season. The highest and lowest elevations on the glacier in 1978 were 5360 and $4950 \mathrm{~m}$ a.s.l., respectively, the centerline length was $1.7 \mathrm{~km}$ and the area was $0.57 \mathrm{~km}^{2}$. The glacier ends at a pond. The altitude of the meteorological station near the base camp, BC (beside the pond), was $4958 \mathrm{~m}$ a.s.l. Seven points on the glacier were considered for the model test, namely L10, L30, L50, L70, L100, U10 and U30 (Fig. 1), as stake observation data and initial snow depths were known for these points. The altitude and area represented by each point are shown in Figure 3, along with the initial snow and ice conditions.

The average air temperature, relative humidity and wind speed were $2.3^{\circ} \mathrm{C}, 88 \%$ and $1.5 \mathrm{~ms}^{-1}$, respectively, 
and total precipitation was $1453 \mathrm{~mm}$ during the observation period, which lasted from 25 May to 25 September 1978.

\subsection{Input data}

\subsubsection{Meteorological data}

The hourly air temperature, $T_{\mathrm{a}}$, observed at the meteorological station, is used in the simulation. A lapse rate of $0.6^{\circ} \mathrm{C}$ / $100 \mathrm{~m}$ (Ageta and others, 1980) is used for estimating temperatures at higher altitudes.

Global radiation, $G_{\mathrm{L} 50}$, was measured from 14 to 29 June 1978 near L50 for a heat-balance study (Ohata and others, 1980). Since $G_{\mathrm{L} 50}$ is more representative of the glacier as a whole, it is compared with global radiation measured at the meteorological station, $G_{\mathrm{MS}}$, collected from 25 May to 25 September 1978, in order to adjust for areal variations in global radiation due to the surrounding topography. By comparing these two datasets, the following relation is obtained for 14-29 June:

$$
G_{\mathrm{L} 50}=1.17 G_{\mathrm{MS}}{ }^{0.92} .
$$

The estimate of global radiation obtained is used for positions up to L50 for the whole observation period. Because global radiation at higher elevations may increase due to high areal albedo, $G_{\mathrm{L} 50}$ is substituted for $G_{\mathrm{R}}$ in Equation (4) to estimate $G_{\mathrm{P}}$ for points higher than L50.

Precipitation at high altitudes occurs both in solid (snow, snow flakes, snow grains, snow pellets and ice pellets) and liquid (rain, drizzle) phases, and mixtures. The type of precipitation observed hourly is used to obtain a relationship between air temperature and relative humidity so as to distinguish snow from liquid precipitation. From the relation used in the model, it was found, for example, that at an air temperature of $2^{\circ} \mathrm{C}$ and $90 \%$ relative humidity, $62 \%$ of the precipitation was snow.

Hourly values of relative humidity, wind speed, precipitation and cloud cover, interpolated from observed data obtained at 3 and 4 hour intervals at the meteorological station, are used in the model. As the basin is small, it is assumed that relative humidity and wind speed do not vary across the basin. As shown by Ageta and others (1980), there was almost no variation in precipitation with altitude, and hence precipitation for the whole glacier is well represented by values from the meteorological station.

\subsubsection{Surface conditions}

The initial surface conditions (Fig. 3), as defined by the relative amounts of new snow, old snow, dirty snow, and ice, changed as a result of continuing accumulation and ablation. Snow that existed on the glacier surface at the beginning of the model calculation is classed as old snow. The observed surface composition at L10 changed to ice after 16 July, following the melting of all old and dirty snow layers, and at L50 after 1 June following the melting of a layer of old snow. Thereafter until 10 September, the ice at L10 and L50 was frequently covered by new snow which, however, melted quickly. The surface was covered by new snow continuously after 10 September. At U30, the observed surface composition was dirty snow from 29 May, except for frequent periods of new snow, and was new snow continuously after 15 August. Surface parameters for different snow and ice types used in the simulation are shown in Table 1. These parameters were measured at or near the seven points on the glacier. The density of ice was assumed to be $850 \mathrm{~kg} \mathrm{~m}^{-3}$ (Kadota and others, 1997). Roughness length and albedo were based on the values used in Ohata and Higuchi (1980) and Ohata and others (1980), respectively.

\section{RESULTS}

The model was run from 25 May to 25 September 1978, as meteorological data are available for this period. A comparison with observed mass balance was done from 10 June to 24 September 1978, the dates on which field measurements were made. Calculated values of the energy-balance components are shown in Table 2, and calculated energy fluxes at L10, L50 and U30 are shown in Figure 4. From Table 2, it is clear that net radiation is the main energy source for melting. The contribution of sensible heat and latent heat is small in comparison. The latent-heat flux at U30 is negative because evaporation exceeded condensation at the beginning of the calculation period. This is a result of low precipitation and high air temperature.

\begin{abstract}
Table 2. Calculated total values $\left(\mathrm{W} \mathrm{m}^{-2}\right)$ of energy-balance components at three points on Glacier AX010, 25 May-25 September 1978 (124 days). Values in parentheses show the percentage of each component in the total energy income
\end{abstract}

\begin{tabular}{lccc}
\hline Component & LI0 & L50 & U30 \\
\hline Net radiation & $7973(85 \%)$ & $6861(83 \%)$ & $5067(91 \%)$ \\
Sensible heat & $961(10 \%)$ & $991(12 \%)$ & $486(9 \%)$ \\
Latent heat & $473(5 \%)$ & $374(5 \%)$ & -52 \\
Heat conduction & -275 & -353 & -120 \\
Energy used for melting & 9132 & 7873 & 5381 \\
& & & \\
\hline
\end{tabular}

A heat-balance study was carried out on the glacier near L50 from 14 to 29 June 1978 by Ohata and Higuchi (1980). Excluding the values on 21 and 24 June due to insufficient data, their results indicate that the total melt calculated from the model during this period is more than twice the actual amount. The main cause for this discrepancy is that the surface albedo calculated by the model is low compared with albedo measured between 14 and 29 June 1978.

Because surface-elevation data at L10, L50 and U30 are available for the entire observation period, observed and calculated surface-elevation changes at these three points were compared (Fig. 5). At U30, the calculated surface elevation is considerably lower than that observed during the first 2 months. It then becomes higher during most of the second 2 months. The changes in the surface elevation at L10 and L50 also show this trend, but not as noticeably. The overestimate of the energy balance by the model due to the low surface albedo during the first half of the season and the lower input of shortwave radiation, especially at U30 and L50 compared to L10, in the second half (Fig. 4) presumably contributed to these results.

Values of mean daily calculated and observed (Ageta and others, 1980) mass balance, averaged over periods of 15 days, are plotted in Figure 6. There is some scatter, but the overall correlation coefficient is 0.77 . The difference $\left(d_{\mathrm{f}}=b-b^{*}\right)$ between observed $(b)$ and calculated $\left(b^{*}\right)$ mass balance is calculated, as statistics involving $d_{\mathrm{f}}$ are a useful check on the accuracy of the model. The mean error is found to be $-0.1 \times 10^{-3}$ mw.e. $d^{-1}$ with a standard deviation of $5.1 \times 10^{-3} \mathrm{~m}$ w.e. $\mathrm{d}^{-1}$. The most likely sources of error are: (a) errors in the relation used to separate snow and rain 

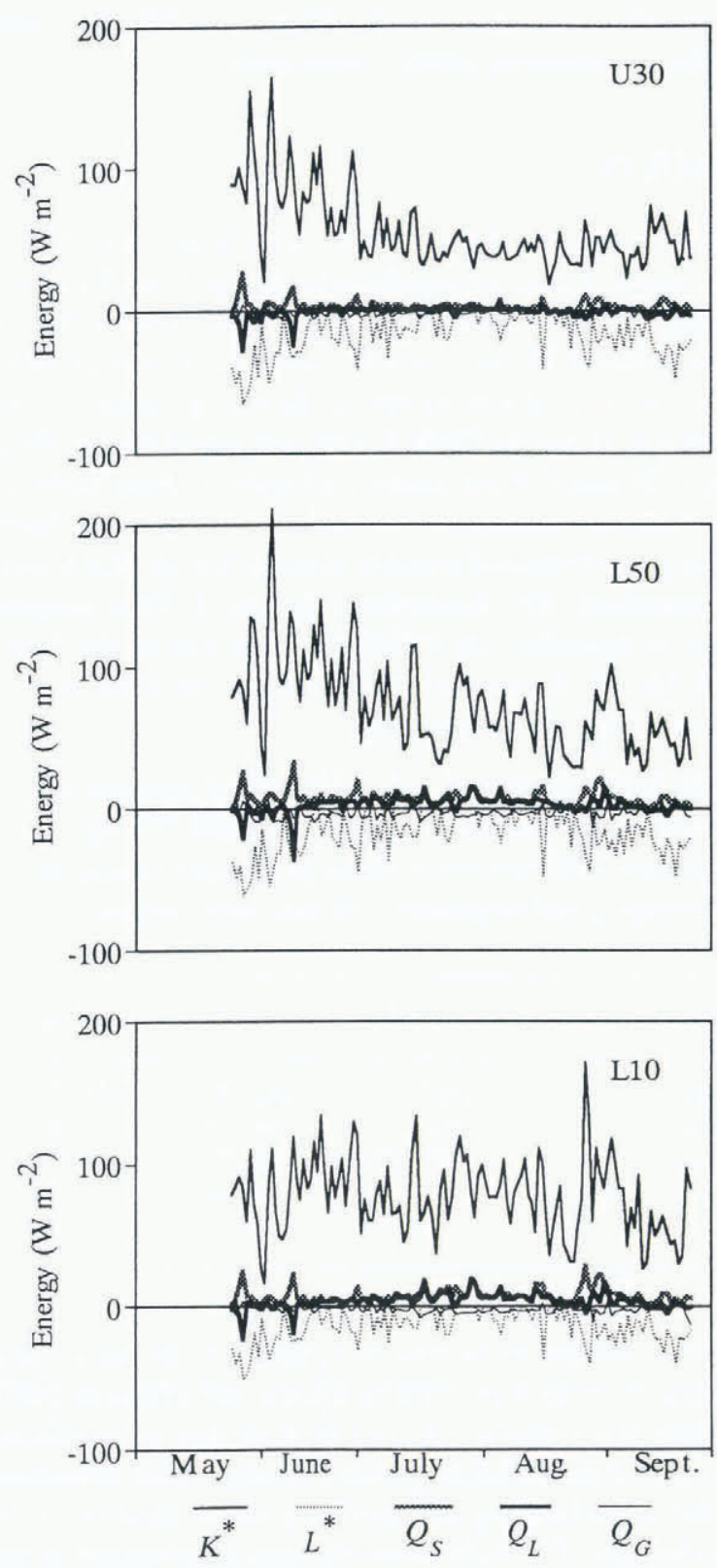

Fig. 4. Variation in calculated energy fluxes at U30, L50 and L10 on Glacier AX010, 25 May-25 September 1978.

during precipitation events; (b) neglect of the small variations with altitude of precipitation that do exist, and the variations with altitude of meltwater percolation and heat transfer due to rainfall; (c) generalization of values of surface parameters averaged from an inadequate number of samples; and (d) extrapolation of meteorological data observed at the base camp to distant sites (note in Figure 5 that errors increase from L10 to U30). However, the overall result of the model is good. The above errors, for example, are smaller than those found by Braithwaite and Olesen (1990) for ablation on two outlet glaciers of the Greenland ice sheet, Qamanarssup sermia (21 months) and Nordbogletscher (14 months), errors $-1.3 \times 10^{-3}$ and $-1.1 \times 10$ ${ }^{3} \mathrm{~m}$ w.e. $\mathrm{d}^{-1}$, respectively. However, the above standard deviation is higher than at Nordbogletscher $\left( \pm 3 \times 10^{-3} \mathrm{~m}\right.$ w.e. $\mathrm{d}$ $\left.{ }^{1}\right)$ but lower than at Qamanarssup sermia $( \pm 7.0 \times 10$ ${ }^{3} \mathrm{mw}$.e. $\mathrm{d}^{-1}$ ). Such differences are probably a consequence, at least in part, of differences in sample size and duration.

The area-averaged mass balance of the whole glacier from 10 June to 24 September 1978 was derived from observations at 32 stakes (Ageta and others, 1980). This value was compared with that calculated by the model at the
Table 3. Results of sensitivity analyses of the model. The mass balance was calculated from 25 May to 25 September 1978 as an area-average for the whole glacier

Input parameters/processes

Mass balance ( $\mathrm{m}$ w.e.)

Reference case

$-0.66^{1}$

Thermodynamic parameters

Difference from reference case

$\%$

With addition of $0.1 \mathrm{~m}$ old snow

Without dirty snow

All densities increased by $50 \mathrm{~kg} \mathrm{~m}^{-3}$

All albedos increased by 0.05

New snow albedo increased by 0.05

All roughness lengths increased by $25 \%$

Meteorological parameter

Using global radiation measured at meteorological station, $G_{\mathrm{MS}}$

\section{Processes}

Multiple reflection with the same areal albedo $\left(\alpha_{\mathrm{P}}=\alpha_{\mathrm{R}}\right)$

Multiple reflection with $\gamma=0.66$

Without screening effect, $V_{\mathrm{f}}=1$

Without thin-snow effect

\footnotetext{
1 The net mass balance for the reference case in the sensitivity tests is more negative than in the comparison with measurements because the model run for the sensitivity tests started on 25 May whereas that for the massbalance comparison started on 10 June. The two weeks between 25 May and 10 June preceded the monsoon and were warm and sunny.
}

seven points mentioned over the same time-span. The calculated and the observed values were in good agreement, namely -0.44 and $-0.46 \mathrm{~m}$ w.e., respectively.

\section{SENSITIVITY TESTS OF INPUT PARAMETERS AND PROGESSES}

Tests of the sensitivity of the glacier mass balance to the input parameters were performed by changing values of the thermodynamic parameters through a range of $10 \%$ of the difference between the maximum and minimum observed values, except for roughness length, which was changed $25 \%$. In the case of global radiation, in one test the value measured at the meteorological observation site was used directly rather than adjusted it for elevation. Other meteorological parameters were the same as in the model run described above. In one test, the multiple-reflection effect was circumvented by setting $\alpha_{\mathrm{P}}=\alpha_{\mathrm{R}}$ in order to study the importance of this effect. The test run with a cloud reflectance of 0.66 represents a condition with developed cumulus cloud rather than the combination of cumulonimbus and cirrus clouds used in the standard model. Test runs without the screening and thin-snow effects were also carried out.

In all of these sensitivity tests, it was found that, intuitively, the dependence is reasonable; no unusual model behavior was detected. Some important results are listed in Table 3.

The mass balance is more sensitive to changes in the amount of dirty snow and in albedo than to changes in the amount of old snow, in density, and in roughness length. This is because surface albedo has a strong effect on net radiation, which is the most important contributor to melting. 


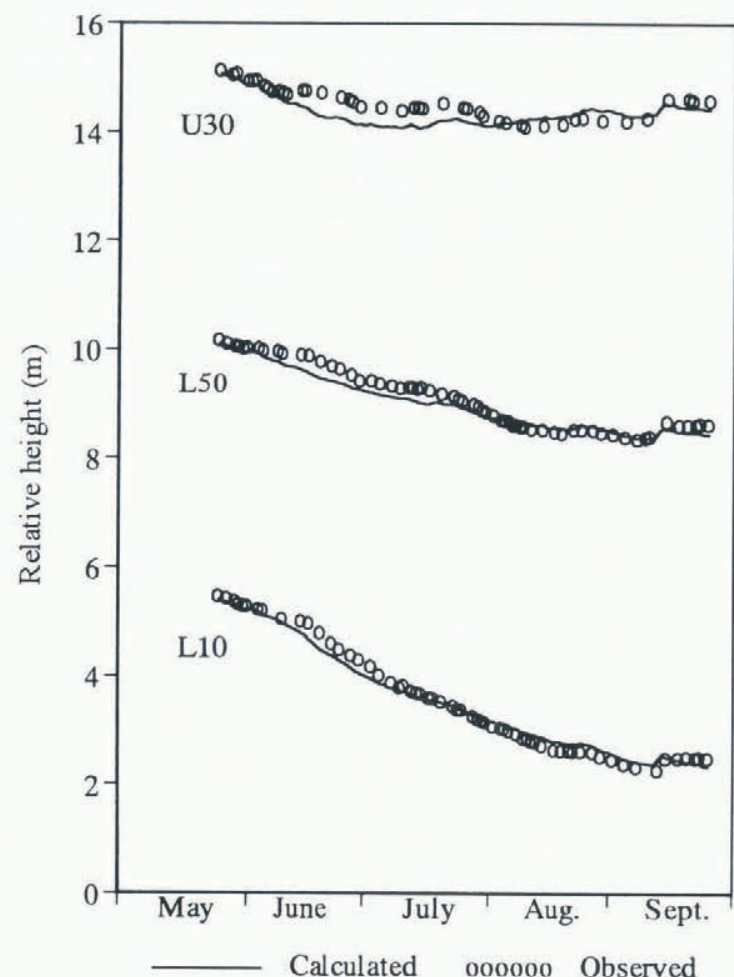

Fig. 5. Observed and calculated surface-elevation changes at U 30, L.50 and L10 on Glacier AXO10 in 1978.

Density and roughness length do not affect the mass balance appreciably because their effect appears only in the heat conduction, and sensible- and latent-heat fluxes, respectively. These heat fluxes make relatively small contributions to the total energy available for melting, compared with the net radiation (Table 2).

The processes which affect or depend upon the surface albedo - thin layers of snow over the ice, multiple reflection, and screening of the mountain walls - play a significant role in the mass-balance sensitivity. Screening by mountain walls has a stronger influence on the receipt of

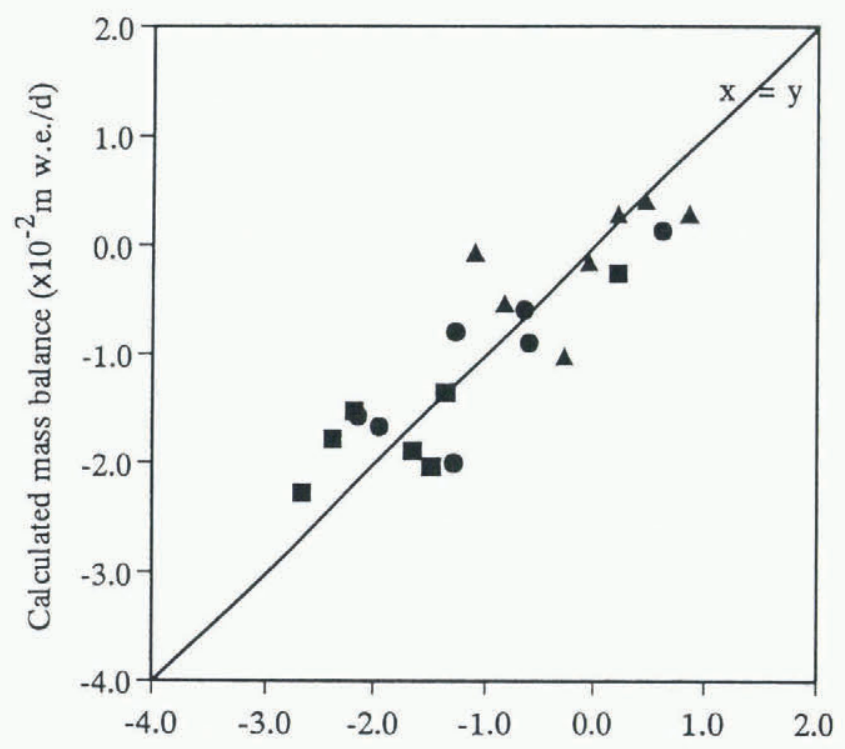

Observed mass balance $\left(\times 10^{-2} \mathrm{~m}\right.$ w.e./d)

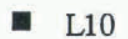

\section{L50 \ U30}

Fig. 6. Observed and calculated mean daily mass balance at L10, L50 and U30 for each half-month from 10 June-24 September 1978 . shortwave than longwave radiation. Therefore, the strong influence of global radiation on mass balance is due to the areal variation of the screening effect and to the multiplereflection effect. Screening of longwave radiation and variations in cloud types, and hence reflectance, have less influence on the mass balance.

\section{SENSITIVITY TESTS OF CLIMATIC PARAMETERS}

Tests of the sensitivity of the mass balance to changes in air temperature, precipitation and relative humidity from 1978 conditions were also performed. The standard deviations $(\sigma)$ from 20-25 years' climatic data, collected in Kathmandu (1336 m a.s.l.) about $120 \mathrm{~km}$ west of the study area, are used to constrain the range of reasonable variations, as long-term data from glacier areas are lacking. Summer mean (JuneSeptember) air temperature and summer total precipitation in Kathmandu for 25 years (1962-86) were found to be $23.4^{\circ} \mathrm{C}$ and $1068 \mathrm{~mm}$, respectively. Similarly, the 20 year (1967-86) mean summer relative humidity in Kathmandu was $82 \%$. The average air temperature and relative humidity in Kathmandu in 1978 were $23.4^{\circ} \mathrm{C}$ and $81 \%$, respectively, and the summer total precipitation was $1175 \mathrm{~mm}$. Thus, summer mean temperature and relative humidity in 1978 are very similar to the long-term mean values, but total precipitation was about $100 \mathrm{~mm}$ higher than the long-term mean. The standard deviations of the long-term air-temperature, precipitation and relative humidity values are $0.4^{\circ} \mathrm{C}$, $13 \%$ and $2 \%$, respectively. Sensitivity tests were carried out for $\pm 1 \sigma$ and $\pm 2 \sigma$ from the values observed in 1978. The results are plotted in Figure 7.

A $0.8^{\circ} \mathrm{C}$ increase in summer air temperature decreases the mass balance by $0.80 \mathrm{~m}$ w.e. compared to 1978 , and a decrease in summer air temperature by $0.8^{\circ} \mathrm{C}$ increases the mass balance by $0.60 \mathrm{~m}$ w.e. Similarly, the mass balance increases by $0.40 \mathrm{~m}$ w.e. when precipitation increases by $26 \%$, and decreases by $0.51 \mathrm{~m}$ w.e. when the precipitation decreases by $26 \%$. The glacier mass balance is more sensitive to air temperature because temperature has a strong influence on glacier melting and also controls the phase of precipitation (snow or rain). Thus, an increase in temperature decreases accumulation due to the decrease in snowfall during a precipitation event, and also intensifies ablation by lowering albedo due to the decrease in the quantity of new snow. The mass balance is also sensitive to precipitation through its effect on albedo as well as on accumulation. Relative humidity affects the longwave radiation and phase of precipitation, but the sensitivity is low in comparison with that of air temperature and precipitation.

Kuhn's (1981) perturbation theory can be applied to this glacier, and the results compared with those of the model. The calculations are carried out with altitudinal gradients of net radiation $-0.08 \mathrm{~W} \mathrm{~m}^{-2} \mathrm{~m}^{-1}$ and heat-transfer coefficient $2.1 \mathrm{~W} \mathrm{~m}^{-2} \mathrm{C}^{-1}$, and without any precipitation gradient from 25 May to 25 September 1978 (124 days). The values at L10, L50 and U30 were used to calculate the netradiation gradient and heat-transfer coefficient. The results show that the equilibrium line rises by $100 \mathrm{~m}$ if the radiation balance increases by $9.3 \mathrm{~W} \mathrm{~m}^{2}$, the accumulation decreases by $300 \mathrm{~mm}$ or the air temperature increases by $4.5^{\circ} \mathrm{C}$. For comparison, Kuhn's model predicts a similar increase in equilibrium-line altitude if the radiation balance increases by $15.4 \mathrm{~W} \mathrm{~m}^{-2}$, the annual accumulation decreases by 

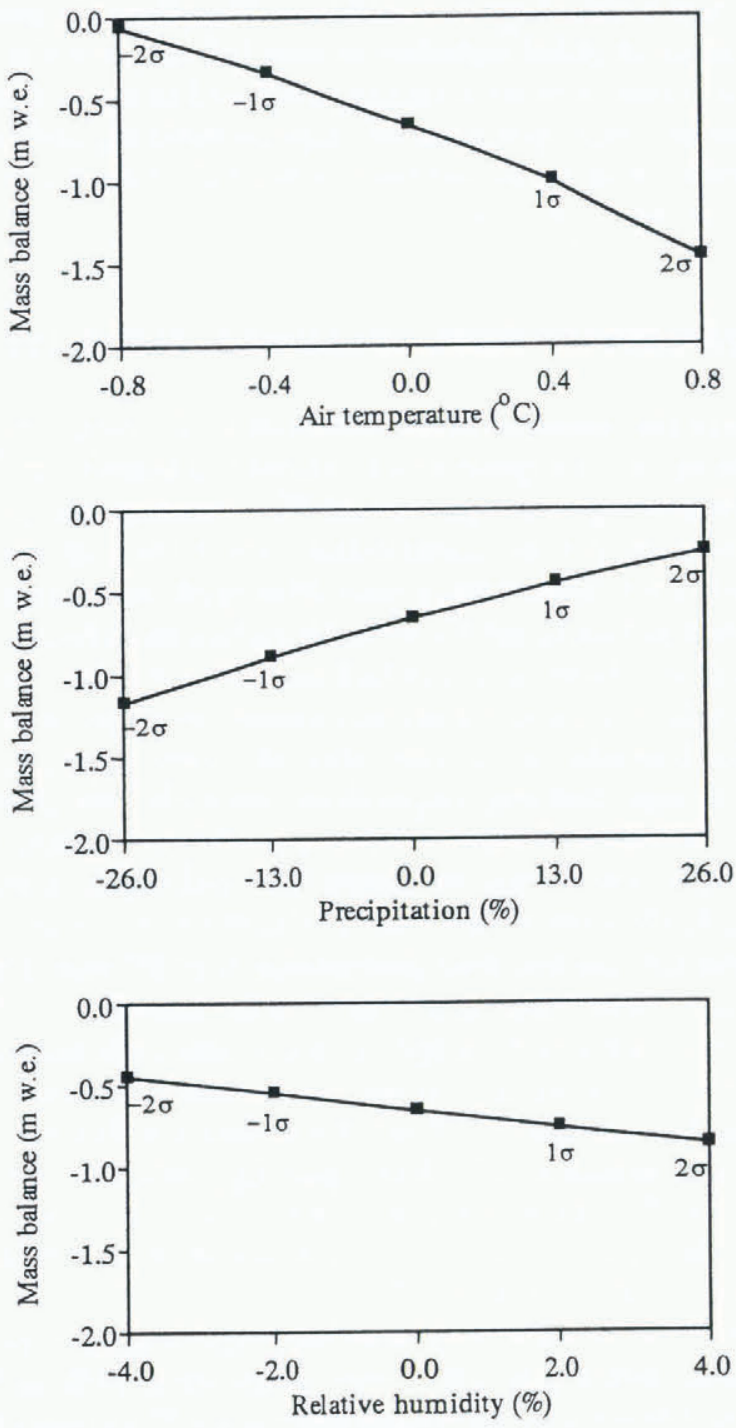

Fig. 7. Response of glacier mass balance to changes in air temperature, precipitation and relative humidity on Glacier AX010, from conditions during summer 1978 (25 May-25 September).

$400 \mathrm{~mm}$, or the free air temperature increases by $0.8^{\circ} \mathrm{C}$. The largest discrepancies between these results are in the values for radiation balance and air temperature. This is probably due to the negative net-radiation gradient and low heattransfer coefficient on this glacier. Although the radiation receipt at lower altitudes is lower than at higher altitudes due to topographic effects, the negative net-radiation gradient is due to the strong absorption of shortwave radiation on the low-albedo ice surfaces at lower altitudes. Another reason may be that several years of data are used in Kuhn's study, but only data from one season are available in the present one. The probability of the occurrence of such fluctuations can be assessed by comparing their magnitude to the long-term variance of seasonal means. Based on the data from Kathmandu, it seems that such fluctuations are unlikely.

\section{CONCLUSIONS}

We have formulated a mass-balance model based on a surface energy balance to calculate spatial and temporal variations of energy-balance components, and hence ablation, over a glacier and successfully applied the model to a small glacier in the Nepalese Himalaya. The model treats shortwave as well as longwave radiation in detail. Surface albedo is calculated internally by programming the model to take into account the effect of thin snow layers on the effective albedo of ice and dirty snow. The screening effect of surrounding mountain walls on the shortwave as well as longwave radiation, and the effect of multiple reflection are also accounted for in the model. A relationship between air temperature and relative humidity is used to distinguish snow from liquid precipitation during precipitation events.

Modelled and observed surface-elevation changes at different altitudes on Glacier AX010 agree well, as does the summer 1978 specific mass balance for the entire ablation season. Discrepancies are largest at the beginning of the season (June) when thin snow layers frequently covered the ice or dirty snow. Heat-balance modelling for this period needs to be improved.

The mass balance is found to be most sensitive to the areal variation of global radiation, multiple-reflection effects, snow or ice albedo and the thin-snow effect. The areal variation in the multiple-reflection and the thin-snow effect is due to processes related to surface albedo. In other words, mass balance is most sensitive to global radiation and surface albedo (cf. Arnold and others, 1996). This is because both have a strong influence on radiation, which dominates the ablation energy. Consideration of effects of thin snow layers and screening of surrounding mountain walls improved the model output significantly. The results of tests of sensitivity to climatic parameters show that the mass balance is quite sensitive to air temperature and precipitation, but only weakly sensitive to relative humidity.

The model, based on well-established physical laws, can be used to study the sensitivity of the glacier mass balance to climatic perturbations. Such studies will elucidate similarities and differences between the glaciers in the Himalaya and other regions. Such a model can also be a tool for studying degree-day models and other empirical relations used to calculate ablation on the Himalayan glaciers. The model described in this paper does not take into account altitudinal variations in precipitation and formation of superimposed ice due to refreezing of percolated meltwater. These processes might need to be included when applying the model to other glaciers. It would also be good to have several years of observational data to validate the results of such a model. This might allow development of a simpler, but still reasonably accurate, model for calculating ablation on Himalayan glaciers.

\section{ACKNOWLEDGEMENTS}

We are grateful to R. LeB. Hooke, M. Kuhn, P. Cutler and M. Nakawo for their valuable comments and suggestions on the first draft of this paper.

\section{REFERENCES}

Ageta, Y. and K. Higuchi. 1984. Estimation of mass balance components of a summer-accumulation type glacier in the Nepal Himalaya. Geogr. Ann., 66A (3), $249-255$.

Ageta, Y., T. Ohata, Y. Tanaka, K. Ikegami and K. Higuchi. 1980. Mass balance of glacier AX010 in Shorong Himal, east Nepal during the summer monsoon season. Seppyo, J. Jpn. Soc. Snow Ice, Special Issue 41, 34-41.

Arnold, N. S., I. C. Willis, M. J. Sharp, K. S. Richards and W. J. Lawson. 1996. A distributed surface energy-balance model for a small valley glacier. I. Development and testing for Haut Glacier d'Arolla, Valais, Swit- 
zerland. 7. Glaciol., 42 (140), 77 -89.

Braithwaite, R.J. and O. B. Olesen. 1990. A simple energy-balance model to calculate ice ablation at the margin of the Greenland ice sheet. F. Glaciol., 36 (123), $222-228$.

Braun, L. N. 1985. Simulation of snowmelt-runoff in lowland and lower Alpine regions of Switzerland. Zürcher Geogr. Schr. 21.

Kadota, T., K. Fujita, K. Seko, R. B. Kayastha and Y. Ageta. 1997. Monitoring and prediction of shrinkage of a small glacier in the Nepal Himalaya. Ann. Glaciol., 24,90-94.

Kuhn, M. 1981. Climate and glaciers. International Association of Hydrological Sciences Publication 131 Symposium at Canberra 1979 - Sea Level, Ice and Climatic Change), 3 - 20.

Kuhn, M. 1989. The response of the equilibrium line altitude to climatic fluctuations: theory and observations. In Oerlemans, J., ed. Glacier fluctuations and climatic change, Dordrecht, etc., Kluwer Academic Publishers, 407-417.

Kuz'min. P. P. 1961. Protsess tayaniya shezhnogo pokrova [Melting of snow cover]. Leningrad, Gidrometeoizdat. (Israel Prog. Sci. Transl., TT71-50095, 1972).

Lee, R. 1962. Theory of the equivalent slope. Mon. Weather Rev., 90, 165-166.

List, R.J. 1971. Smithsonian meteorological tables. Sixth revised edition. Washington, DC, Smithsonian Institution Press. (Smithsonian Miscellaneous Collections 114 .

Marks, D. 1979. An atmospheric radiation model for general alpine application. In Colbeck, S. C. and M. Ray, eds. Modeling of Snow Cover Runoff, 26-28 September 1978, Hanover, New Hampshire. Proceedings. Hanover, NH, U.S. Army Corps of Engineers. Cold Regions Research and Engineering
Laboratory, 167-178.

Munro, D. S. 1991. A surface energy exchange model of glacier melt and net mass balance. Int. 7. Climatol., 11 (6), 689-700.

Oerlemans, J. 1993. A model for the surface balance of ice masses. Part 1. Alpine glaciers. Z. Gletscherkd. Glazialgeol., 27-28, 1991-1992, 63-83.

Oerlemans, J. and N. C. Hoogendoorn. 1989. Mass-balance gradients and climatic change. f. Glaciol., 35(121), 399-405.

Ohata, T. 1991. Effect of snow/ice-cloud radiative interaction on the global radiation at the surface of snow and ice masses. International Association of Hydrological Sciences Publication 208 (Symposium at St Petersburg 1990 Glaciers-Ocean-Atmosphere Interactions), 495-506.

Ohata, T. and K. Higuchi. 1980. Heat balance study on glacier AX010 in Shorong Himal, east Nepal. Seppyo, J. Jpn. Soc. Snow Ice, Special Issue $41,42-47$.

Ohata, T., K. Ikegami and K. Higuchi. 1980. Albedo of glacier AX010 during the summer season in Shorong Himal, east Nepal. Seppyo, 7. Jpn. Soc. Snow Ice, Special Issue 41, 48-54.

Oke, T. R. 1987. Boundary layer climates. Second edition. London, Methuen; New York, Routledge Press.

Reynolds, D.W., T. H. vonder Haar and S. K. Cox. 1975. The effect of solar radiation absorption in the tropical troposphere. f. Appl. Meteorol., 14, $433-443$.

Van Dusen, M. S. 1929. Thermal conductivity of non-metallic solids. In Washburn, E.W., ed. International critical tables of numerical data: physics, chemistry and technology. Vol. 5. New York, McGraw Hill, 216-217.

MS received 13 August 1998 and accepted in revised form 10 May 1999 